\title{
Breve evolución histórica de la discriminación lingüística en el Perú
}

\section{A Brief Historical Evolution of Linguistic Discrimination in Peru}

\author{
Marco Antonio Zamora Huamán \\ Universidad Nacional Mayor de San Marcos, Lima, Perú \\ marco.zamora@unmsm.edu.pe
}

\begin{abstract}
Resumen
La historia es un proceso de acontecimientos que forjan el devenir de una sociedad en su conjunto. La lengua, por su lado, no está exenta de tal exógena acometida, ya que, en el caso de la discriminación lingüística, es víctima de una serie de hechos sociales que han robustecido a lo largo de estos siglos el derrotero de la mayoría de lenguas amerindias del Perú, condenándolas a una agonía que hasta hoy persiste. El presente trabajo trata de dar una mirada oceánica a algunos de los hechos históricos que permitieron y siguen permitiendo que el fenómeno planteado continúe latente entre nosotros.
\end{abstract}

Palabras claves: Perú; historia; discriminación lingüística.

\begin{abstract}
History is a process of events that forge the future of a society as a whole. The language, on the other hand, is not exempt from such an exogenous rush that, in the case of linguistic discrimination, is the victim of a series of social events that have strengthened throughout these centuries the course of most Amerindian languages of Peru, condemning them to an agony that persists until today. The present work, tries to give an oceanic look to some of the historical facts that allowed and continue to allow the proposed phenomenon to continue beating among us.
\end{abstract}

Keywords: Peru; history; linguistic discrimination. 


\section{Introducción}

La discriminación en el Perú es un fenómeno social de carácter transversal que puede dividirse en manifestaciones particulares de discriminación, pero sin aislarse unas de otras; es decir, se conjugan variantes étnicas, culturales, socioeconómicas, entre otras, siendo una de ellas la discriminación lingüística. El abordaje del referido fenómeno puede establecerse desde distintos planos: la actual interacción lingüística que se genera entre hablantes de diferentes lenguas en el país, las relaciones de poder entre una lengua y otra, el rol de la educación con relación a la discriminación entre lenguas o sus variantes, el papel del Estado en la implementación sólida de políticas en contra de la discriminación lingüística, la función de los gobiernos de mantener dicha implementación con carácter de prioridad nacional, etcétera. Sin embargo, todos estos pasajes repletos de ríspidos caminos por donde nos trae la discriminación lingüística tienen un origen, un fundamento histórico y evolutivo que contribuyó medularmente tanto en el ideal del colectivo social como en el papel que tendría cada lengua en la actualidad. Es decir, retrotraernos al pasado histórico de este fenómeno, y con él a sus orígenes, nos suministrará de mejores herramientas para comprender el problema como tal, y decidir entre la continuación o el cambio.

\section{El origen de la discriminación lingüística en el perú}

¿Por qué discriminar lingüísticamente a alguien en nuestra sociedad? Una posible explicación a dicha pregunta es producto de los diversos procesos sociales que vienen desde nuestro pasado colonial, en el cual se crearon sistemas de jerarquías sociales muy marcados entre los colonos y los colonizados, así como un sinnúmero de castas que fueron interactuando en medio de relaciones de poder claramente asimétricas que abarcaban aspectos étnicos, económicos, lingüísticos, culturales, entre otros. Todo esto propició que, posteriormente, a lo largo de nuestra historia, fueran transformándose en medios idóneos de discriminación entre las clases dominantes y las subordinadas.

La ideología política española, fundada en la tradición católica y medieval, partía de la premisa de que la forma de organizar saludablemente la sociedad era sobre la base de constituir claras jerarquías sociales, siguiendo así los postulados aristotélicos y tomistas entonces prevalentes. Estas jerarquías se justificaban por la necesidad de que diferentes estamentos sociales cumplieran 
Los términos para el color negro y su desarrollo semántico en las lenguas...

en forma adscrita funciones especializadas a fin de que el conjunto se desenvolviera con normalidad. (Cotler, 2005, p. 60) ${ }^{1}$

Si bien es cierto que durante la colonia no se puede hablar propiamente de discriminación hacia las lenguas, sino más bien de jerarquización y subordinación (ver Portocarrero, 1992), de hablantes de una sociedad, podemos decir, de alguna manera, que los inicios de la discriminación lingüística del castellano hacia las lenguas amerindias del Perú fue germinando en este periodo de la historia.

Es importante precisar que, en los inicios y durante la estructuración de la colonia, se buscó evangelizar al pueblo indígena. Estas primeras estrategias tenían como objetivo comunicarse por medio de las lenguas autóctonas de la región, ya que facilitaría una vinculación directa entre el colonizado y el interés del colonizador. Desde esta perspectiva vemos que, disuelto el imperio inca, la lengua general (el quechua) conservó su estatuto de lengua vehicular mientras persistió una política liberal que respetara las diferencias culturales propias de cada pueblo (sin perder la real jerarquía de estas). Hasta entonces, el quechua, aún sin codificación, era la lengua imperial de la organización administrativa, así como, por la acción de los misioneros, de la religión católica. Solo frente a la imposición de lo extranjero, la lengua castellana, es que la lengua, otrora «lengua imperial», se volvió un símbolo identitario en la conformación de una comunidad lingüística distinta (Gumperz, 1962).

Con estas primeras medidas adoptadas para las lenguas amerindias, la lengua fue una herramienta de poder, ya que, mediante esta, el vencedor se comunicaba con el vencido y establecían lazos de convivencia. Los españoles vieron en la lengua indígena la oportunidad para internarse en el mundo del indígena, poder entenderlo y, mediante eso, estructurar un nuevo régimen económico y político, por tales razones el uso del quechua u otras lenguas al inicio del virreinato, más que un aporte lingüístico para la comunicación, constituyó una acción de glotopolítica (Arnoux, 200o). Este criterio fue empleado eminentemente como una estrategia mediante el «discurso» para establecer conductas reguladas en la población aborigen y no propiciar conflictos ni rebeliones que enturbiaran el nuevo orden colonial.

1 La administración colonial escinde bajo aspectos administrativos, jurídicos, políticos, sociales y económicos la República de españoles y la República de indios, quedando claro (en el ideal) la superioridad inobjetable del primero bajo una suerte de discriminación etnocultural. 


\section{Marco Antonio Zamora Huamán}

Hay una eficacia propiamente simbólica, cuya realización por excelencia es sin duda el derecho, es una violencia que se ejerce, si puede decirse, en las formas, poniendo formas. Poner formas es dar a una acción o a un discurso la forma que es reconocida como conveniente, legítima, aprobada, es decir, una forma tal que se puede reproducir públicamente, frente a todos, una voluntad o una práctica que, presentada de otra manera, sería inaceptable. (Bourdieu, 1987, p. 90)

Al transcurrir este periodo, se tuvieron que hacer reformas y "políticas lingüísticas $»^{2}$ dentro de la colonia, las cuales fueron producto principalmente de las constantes rebeliones y de otros intereses que iban en desmedro de la adecuada gobernabilidad de la colonia en Latinoamérica. Tales medidas, "por aspectos estratégicos», fueron las de ejercer una suerte de monolingüismo colonial en función al castellano como lengua predominante, llegando incluso, en varias épocas de la colonia, a prohibirse hablar el quechua o alguna otra lengua amerindia, esencialmente por dos razones: querer ejercer el poder total de las colonias, y por temor a rehabilitar la esencia cultural e ideológica de los indígenas, cristalizada en levantamientos o rebeliones que puedan poner en jaque el orden estamental, no solo del virreinato peruano, sino incluso el de la región.

A la política liberal española que consideró la lengua como un medio de penetración en la cultura del indio, permitiéndole aún la conservación de su cultura y costumbres, le sucederá una política dirigista, que impondrá en 1770 la castellanización de las colonias." (Porras Barrenechea, 1963). Este proceso o «involución» que partió desde respetar a la lengua como vehículo de comunicación y a sus respectivas culturas, hasta su persecución y erradicación, siempre tuvo el mismo resultado negativo para las lenguas amerindias. A partir de la colonización europea, las lenguas andinas entraron en concurrencia con el castellano y sufrieron consecuencias drásticas: perdieron prestigio, retrocedieron sus funciones sociales, se disminuyeron sus números de hablantes, y, si es que sobrevivieron, su evolución interna fue arrestada. La evolución interna de una lengua se relaciona intrínsecamente con su desarrollo externo, vale decir, con su vigor social y político, y con las actitudes culturales que influyen en su destino. En situaciones de colonización lingüística como la que prevalece en los andes, como dice Sichra (2003, citado

2 No nos referimos a una política lingüística, propiamente dicha, como se entiende en la actualidad, sino a un modo «improvisado» de fijar el interés de la colonia, por razón de coyunturas de gobierno. 
Los términos para el color negro y su desarrollo semántico en las lenguas...

por Howard, 2007), la continua vitalidad de una lengua hace indispensable una explicación que tome en cuenta el papel de las ideologías lingüísticas.

Es resaltante que, en esta sociedad colonial que jerarquizó todas las relaciones sociales y económicas, haciendo algunas más prestigiosas y a otras más desprestigiadas, la mayoría de las lenguas fueran perdiendo su prestigio y la fuerza comunicativa que tenían en otro momento. Evidentemente, todo esto no fue de la noche a la mañana, y, además, no solo constituyó un despliegue fríamente político y administrativo. Hubo un menoscabo interno al hablante durante un periodo importante de la historia, ya que estos interlocutores, en su mayoría, hablaban una lengua que había sido el vehículo por excelencia para la comunicación del incario: el quechua. «El espacio territorial cubierto por el quechua es el resultado no solamente de su otrora carácter de vehículo oficial del imperio incaico sino también, tras la caída de éste, de su rol fundamental de lengua de relación y de afianzamiento del imperio colonial español.» (Cerrón-Palomino, 1987, p. 49).

\section{El legado colonial}

Este legado monolingüe en el Perú prosperó y se abrió paso incluso después de la caída del virreinato. Durante los siguientes periodos de la independencia y de la república, la falta de representatividad multiétnica en el Perú, la predominancia del castellano como vehículo oficial de comunicación en el territorio, y la estructura social jerárquica del país que posibilitó el agrupamiento de un sector minoritario ${ }^{3}$ de la población en el poder político, social y económico, mantuvo a las demás lenguas relegadas y sin estatus político ni social. Es decir, el siglo XIX no trajo una reivindicación social al indígena, pero sí un fortalecimiento del mestizo que, en la práctica, continuaba albergando consigo un sentimiento de superioridad ante las culturas aborígenes como tal, mientras, a nivel lingüístico, significó la continuación de una subestimación y el punzante menosprecio a las lenguas vernáculas.

Los inicios del siglo xx en el Perú, conocido como la República Aristocrática, maduró la idea de una oligarquía piramidal que siempre se mantuvo de espalda a los pueblos andinos. La amazonia fue cobrando protagonismo debido a la fiebre de caucho, el cual significó la explotación y extermino de muchos pobladores

3 La independencia del Perú como tal fue un logro exclusivo de criollos y mestizos, mientras la participación del indígena fue complementaria y desentendida con los objetivos de los que serían sus nuevos «superiores» sociales. 


\section{Marco Antonio Zamora Huamán}

de estos grupos étnicos en detrimento de sus lenguas y culturas. Con el pasar de las décadas, a mediados de dicho siglo, la migración del campo a la ciudad enfrentó, de manera más frontal, a peruanos de diversas etnias, y cuyo medio de comunicación no fue el de una lengua a lengua, sino de una variedad de castellano a otra. Esto evidenció una brecha social que se trató de erradicar a nivel social y educativo en la capital y gran parte del país. Todo este primer contacto fue estableciendo o confirmando, en la psicología del migrante, la idea de inferioridad ante un limeño cada vez entremezclado y convencido de una aparente superioridad ante el indígena. Este fenómeno de exclusión iría siendo paulatinamente caldo de cultivo para lo que posteriormente sería la lucha armada (Sendero Luminoso y MRTA), cuyo capítulo en la sociedad fue el común denominador de una desigualdad todavía patente en el país ${ }^{4}$.

En la actualidad, si bien la Constitución Política vigente determina, hace solo unas décadas, el uso y respeto de las demás lenguas, como manifestaciones de libertad y democracia, lo cierto es que todo el aparato social y político continúa siendo en castellano, y, entre estos, el sistema educativo, que fue internalizando durante generaciones, mediante la enseñanza, la correcta pronunciación y uso generalizado del castellano estándar, la superioridad explícita e implícita de esta lengua y una mirada completamente clasista a lo andino y amazónico. Todo esto produjo una falsa y equívoca creencia sobre las lenguas y dialectos de nuestro país, y la paulatina preferencia por parte de los no hablantes de castellano hacia esta, lo que ocasionó el abandono o desuso de las otras.

A lo anterior, no podemos soslayarle el creciente auge de las telecomunicaciones en las últimas décadas del siglo xx. La difusión variopinta de programas de todo corte derivó, en su mayoría, a una mirada indiferente e incluso abusiva sobre las culturas minoritarias del país. Programas cómicos, de espectáculo, noticiosos, novelas, etcétera. Todos ellos, en conjunto, dibujaron permanentemente, en el mejor de los casos, una mirada olvidada del indígena, un escarnio palmario a la mayoría de sus manifestaciones culturales entre las cuales se incluía su lengua. Por otro lado, la vulneración de las minorías culturales como manifestación globalizadora y reforzada por un prominente capitalismo excluyente y deshumanizante

4 De acuerdo a las conclusiones generales esgrimidas por la CVR en su punto 6, el 75\% de las víctimas fatales del conflicto armado interno tenían el quechua u otras lenguas nativas como idioma materno. 
Los términos para el color negro y su desarrollo semántico en las lenguas...

de constantes cambios vertiginosos que dejaban rezagado cualquier intento de progreso en culturas con claras desventajas tecnológicas y educativas.

Hoy en día, en el siglo XXI, todos los procesos de castellanización antes mencionados se continúan efectuando, siendo el castellano el vehículo de comunicación por antonomasia en nuestro país, en lugar de una correcta convivencia con oportunidades lingüísticas para todos. Si bien no se puede ser mezquinos en mencionar que se han impulsado en las últimas décadas programas y políticas que han servido para llevar la lengua del nativo hacia el mismo nativo en cuestiones de educación, e incluso a la sociedad en general, dichos intentos inclusivos continúan siendo insuficientes por no tratarse de programas orgánicos y realmente institucionales.

Si bien hablar de discriminación seguirá siendo un asunto complejo por el sinnúmero de aspectos que se deben de tomar en consideración, el componente histórico de nuestro país nos da claras muestras de cómo se fueron entretejiendo los actos de exclusión y discriminación, que, a pesar de los recientes intentos por palearlo, continúan pululando a sus anchas en nuestro país.

\section{Referencias bibliográficas}

Arnoux, E. (2000). La glotopolítica: Transformaciones de un campo disciplinario. Lenguajes: teorías y práctica (pp. 3-27). Buenos Aires: Secretaría de Educación, GCBA.

Bourdieu, P. (1987). La codificación. En Autor, Cosas dichas. España: Gedisa.

Cerrón Palomino, R. (1987). Lingüística quechua. Cuzco: Centro de Estudios Rurales Andinos «Bartolomé de las Casas».

Comisión de la Verdad y Reconciliación (CVR). (2004). Hatun willakuy: Versión abreviada del informe final de la comisión de la verdad y reconciliación. Lima: Autor.

Cotler, J. (2005). Clases, Estado y Nación en el Perú. Lima: Instituto de Estudios Peruanos.

Gumperz, J. (1962). Types of Linguistic Communities. Anthropological Linguistics. 4(1), 28-40.

Howard, R. (2007). Por los linderos de la lengua. Ideologías lingüísticas en los Andes. Lima: Instituto de Estudios Peruanos, Instituto Francés de Estudios Andinos, Pontificia Universidad Católica del Perú. 


\section{Marco Antonio Zamora Huamán}

Porras Barrenechea, R. (1963). Fuentes históricas peruanas. Lima: Instituto Raúl Porras Barrenechea.

Portocarrero, G. (1992): Discriminación Social en el Perú de hoy. En Nelson Manrique, 500 años después... ¿el fin de la historia? Lima: Escuela para el desarrollo.

Zamora, M. (2012). Discriminación léxica en jóvenes hablantes de castellano regional en diversos colegios del cono norte de la provincia de Lima (Tesis de Licenciatura). Universidad Nacional Mayor de San marcos, Lima. 